\title{
Elucidation of the Average Molecular Structure of Argentinian Asphaltenes
}

\author{
Yanina B. Bava,,$^{\dagger}$ Mariana Geronés, ${ }^{* \dagger}$ David Buceta, ${ }^{\ddagger}{ }^{\oplus}$ Darío de la Iglesia Rodríguez, ${ }^{\ddagger}$ \\ M. Arturo López-Quintela, ${ }^{\ddagger \odot}$ and Mauricio F. Erben, ${ }^{*}+\odot$ \\ ${ }^{\dagger}$ CEQUINOR (UNLP, CONICET CCT-La Plata) Departamento de Química, Facultad de Ciencias Exactas, Universidad Nacional \\ de La Plata, Blvd. $120 \mathrm{~N}^{\circ} 1465$, La Plata CP 1900, Argentina \\ ${ }^{\ddagger}$ Laboratory of Magnetism and Nanotechnology, Technological Research Institute, University of Santiago de Compostela, Santiago \\ de Compostela E-15782, Spain
}

Supporting Information

ABSTRACT: Petroleum asphaltenes were separated from three different Argentinian crude oils. The asphaltene fractions were extracted by precipitation employing $n$-pentane and $n$-heptane solvents, and the coprecipitated resins were removed via Soxhlet extraction. The asphaltenes were characterized by elemental analysis, thermogravimetric analysis, laser desorption ionization mass spectrometry, Fourier-transform infrared spectroscopy, proton nuclear magnetic resonance, powder X-ray diffraction, and Raman spectroscopy. It was found that the asphaltene fractions present both a higher content of heteroatoms and a major degree of aromaticity, when $n$-heptane is employed. Average structural parameters were obtained by a comprehensive analysis of the experimental data, including those describing the central polycyclic aromatic hydrocarbon (PAH) cores and lateral chains. Thus, a hypothetical average molecular structure is proposed for the Argentinian asphaltenes. The average model molecules have a nucleus of PAHs arranged as pericondensed systems of 4-6 fused aromatic rings, with naphthenic groups and/or alkyl chains of 5-10 carbon long attached.

\section{INTRODUCTION}

Asphaltene is the heaviest and more complex fraction of petroleum. They are usually defined operationally as the fraction of crude oil insoluble in $n$-pentane or $n$-heptane and soluble in toluene. ${ }^{1,2}$ This fraction is called as the "cholesterol of petroleum" because of the well-known problems caused by asphaltenes in the petroleum production, transportation, refining, and storage, being responsible for the blockage of wellbore, plugging of pipelines, and the deactivation of catalysts used during refining process. ${ }^{3}$ Because of the negative impact of asphaltenes in the petroleum industry, it is necessary to know more about the fundamental aspects on this complex fraction. Actually, studies about petroleum asphaltenes have rapidly increased because of the increasing exploitation of heavier crude oil sources.

As highlighted by Mullins, ${ }^{4}$ it is strictly necessary to know the chemical structure of asphaltenes to predict their behavior in real systems. Therefore, the state of the art in this area focuses on the identification of the constituents of the asphaltene fraction by using high-resolution mass-spectrometry (petroleomics) complemented with the knowledge of their molecular structure. Despite the numerous studies done in this area, the asphaltene structure remains as one of the most controversial topics in this field.

It is widely accepted that the asphaltene fraction consists of a complex mixture of hydrocarbons with polycyclic aromatic hydrocarbons (PAHs), substituted by aliphatic chains and heteroatoms such as oxygen, sulfur, and nitrogen and in smaller quantity metals, mainly vanadium and nickel. On the other hand, the asphaltene molecular weight continues to be the subject of a large controversy, showing values dependent on the technique employed, that differ in one or two orders of magnitude. ${ }^{5}$ Several studies based on high-resolution mass spectrometry as well as molecular diffusion techniques conclude that the asphaltenes have a molecular weight distribution (MWD) with a mean at $\sim 750 \mathrm{Da}$, varying from 500 to $1200 \mathrm{Da}^{3,4}$

To determine which is the dominant molecular architecture in asphaltenes is another topic of interest. There are two competing models proposed: the "island" or Yen-Mullins model and the "archipelago" model. The "island" or YenMullins model ${ }^{6}$ is based on a single polyaromatic core with pendant aliphatic chains, whereas the "archipelago" model 7,8 consists of smaller aromatic groups linked by aliphatic bridges. There exists a consensus about the dominance of the island molecular architecture for asphaltenes that it is supported by results where the $\mathrm{PAH}$ contains approximately seven fused rings (varying between 4 and 10) substituted by alkyl side chains ( 7 carbons long on average) for petroleum asphaltenes and functional groups with heteroatoms. ${ }^{4,9,10}$ Nevertheless, the archipelago model cannot be completely discarded, and recent studies show evidence about the presence of both island and archipelago architectures in petroleum asphaltenes. ${ }^{11}$ It has been recognized that one of the main difficulties in the study of asphaltene's structure can be attributed to their tendency to form aggregates, which leads to further challenges in the analysis.

Received: December 13, 2018

Revised: March 5, 2019

Published: March 5, 2019 
Table 1. List of Asphaltene Content in Different Crude Oils Extracted with $n$-Pentane and $n$-Heptane Solvents; Percentage Atomic Content and Various Atomic Ratios Obtained by Elemental Analysis; Number-Average Molecular Weight Values and Weight-Average Molecular Weight Values; and Polydispersity Index from LDI-MS

\begin{tabular}{|c|c|c|c|c|c|c|}
\hline \multirow{2}{*}{$\begin{array}{l}\text { sample } \\
\text { solvent }\end{array}$} & \multicolumn{2}{|c|}{ A1 } & \multicolumn{2}{|c|}{$\mathrm{A} 2$} & \multicolumn{2}{|c|}{ A3 } \\
\hline & $\mathrm{C} 5$ & $\mathrm{C} 7$ & $\mathrm{C} 5$ & $\mathrm{C} 7$ & $\mathrm{C} 5$ & $\mathrm{C} 7$ \\
\hline asphaltenes content & 7.2 & 0.5 & 2.4 & 0.1 & 1.7 & 0.3 \\
\hline \multicolumn{7}{|c|}{ Elemental Analysis } \\
\hline$\% \mathrm{C}$ & 88.14 & 84.74 & 86.83 & 84.93 & 85.46 & 80.38 \\
\hline$\% \mathrm{H}$ & 9.79 & 8.39 & 9.18 & 8.57 & 9.42 & 8.69 \\
\hline$\% \mathrm{~N}$ & 1.23 & 1.15 & 1.09 & 1.30 & 1.01 & 1.04 \\
\hline$\% \mathrm{~S}$ & 0.35 & 1.76 & 1.43 & 0.41 & 2.69 & 2.59 \\
\hline$\% \mathrm{O}$ & 0.49 & 3.96 & 1.47 & 4.79 & 1.42 & 7.30 \\
\hline $\mathrm{H} / \mathrm{C}$ & 1.33 & 1.19 & 1.27 & 1.21 & 1.32 & 1.30 \\
\hline $\mathrm{S} / \mathrm{C}$ & 0.0039 & 0.0207 & 0.0164 & 0.0048 & 0.0117 & 0.032 \\
\hline $\mathrm{N} / \mathrm{C}$ & 0.0139 & 0.0135 & 0.0125 & 0.015 & 0.0118 & 0.0129 \\
\hline $\mathrm{O} / \mathrm{C}$ & 0.0055 & 0.046 & 0.0169 & 0.0563 & 0.016 & 0.0906 \\
\hline \multicolumn{7}{|c|}{ LDI } \\
\hline$M_{\mathrm{n}}$ & 1459 & 1366 & 1338 & 1411 & 1357 & 1324 \\
\hline$M_{\mathrm{w}}$ & 1684 & 1547 & 1534 & 1607 & 1546 & 1472 \\
\hline$D_{\mathrm{m}}$ & 1.15 & 1.13 & 1.15 & 1.14 & 1.14 & 1.11 \\
\hline
\end{tabular}

Very recently, the photochemical properties of Argentinian asphaltenes, in particular, its ability for producing singlet oxygen, have been reported. ${ }^{12}$ To our knowledge, characterization and structural studies have not been performed up to now for asphaltenes present in Argentinian oils. For this reason, the aim of this work is the elucidation of the asphaltene average molecular structure from Argentinian crude oils through a wide variety of spectroscopy techniques. Thus, six asphaltene samples have been studied by using elemental analysis, laser desorption ionization mass spectrometry (LDIMS), thermogravimetric analysis (TGA), Fourier-transform infrared spectroscopy (FTIR), nuclear magnetic resonance $\left({ }^{1} \mathrm{H}\right.$ NMR) spectroscopy, X-ray diffraction (XRD) techniques, and Raman spectroscopy. Structural parameters such as the dimension of $\mathrm{PAH}$; the amount of rings per molecule; and the length of alkyl chains, degree of substitution, and aromaticity were obtained and analyzed together. On this basis, the average molecular structure for asphaltenes is proposed.

\section{EXPERIMENTAL METHODS}

Asphaltenes Extraction. Three samples of Argentinian crude oils (C1, C2, and C3) obtained from San Jorge gulf basin in Comodoro Rivadavia, Loma Negra field complex on the Rio Negro Norte Block in southeastern Neuquen and La Salina field in La Pampa (indicated in Figure S1) were employed for asphaltenes extraction using a modified IP-143 standard method. ${ }^{13}$ The API gravities for the crudes oils $\mathrm{C} 1, \mathrm{C} 2$, and $\mathrm{C} 3$ were determined, following the procedure describe in ASTM D4052 method ${ }^{14}$ having values of $26.93^{\circ}, 36.47^{\circ}$, and $33.59^{\circ}$, respectively. Six different Argentinian asphaltene samples (A1, A2, and A3) were isolated by the addition of an excess of $n$ pentane (C5) or $n$-heptane (C7) solvents to each of the three crude oils (Table 1). The experimental condition used for the extraction method, as the volume ratio and the contact time, is recommended in previous works to ensure stable asphaltene yields. ${ }^{15-19}$

The asphaltene fractions have been precipitated from crude oils by solvent addition in a ratio of $1 \mathrm{~g}$ of crude oil per $40 \mathrm{~cm}^{3} n$-alkane. The mixture was left to equilibrate for $16 \mathrm{~h}$, and the precipitated asphaltenes were separated from maltenes ( $n$-alkane soluble fraction) by vacuum filtration through $2 \mu \mathrm{m}$ Whatman filter paper in Buchner. The asphaltenes retained on the filter paper contains coprecipitated resins and are considered to be unwashed asphaltenes. Thus, resins were removed via Soxhlet extraction with boiling $n$-alkane during $6 \mathrm{~h}$ until no coloration was observed in the solvent extractor. To remove the nonasphaltene species present in the crude oil that are insoluble in $n$-alkane, the resin-free asphaltene samples were dissolved in toluene and then filtered. Toluene was evaporated from the solution, and finally the reprecipitated solids were dried in a vacuum oven at $115^{\circ} \mathrm{C}$ until they reached a constant weight. Asphaltene precipitation experiments were performed in duplicated and the asphlatene yields were calculated with a relative error between 2 and $4 \%$. Asphaltene yields from the three crude oils using $n$-pentane and $n$-heptane are given in Table 1 . The $n$-pentane and $n$-heptane solvents used were of analytical grade.

It was observed that for the three crudes employed, the amount of asphaltene precipitated enhanced when using $n$-pentane as the precipitating medium. This agrees with fact that for a given dilution ratio, the amount of precipitates decreases with the increasing solvent carbon number. ${ }^{19}$ It is also expected that resin content in the precipitate decreases in a similar trend. It was also observed that for both $n$-pentane and $n$-heptane solvents, the asphaltene yields were always higher for crude oil C1, followed by crude oil C2 and finally crude oil $\mathrm{C} 3$. This shows that the quantity and properties of the asphaltene constituent in crude oils depend on the origin of the crude oil. $^{15}$

Experimental Techniques. The $\mathrm{C}, \mathrm{H}, \mathrm{N}$, and $\mathrm{S}$ contents were obtained by the Thermo Finnigan Elemental Analyzer FLASH 1112. For the measure was employed about $3 \mathrm{mg}$ of sample and a combustion temperature of $1020{ }^{\circ} \mathrm{C}$. The oxygen content was determined by difference.

Laser desorption ionization mass spectrometry (LDI-MS) experiments were performed on a Ultraflex III (Bruker) instrument, with a laser Smartbeam 200. The laser repetition rate is tunable from 1 to $200 \mathrm{~Hz}$. The TOF-MS spectra were recorded in the range between 500 and $5020 \mathrm{Da}$ with a matrix suppression reflection up to $450 \mathrm{Da}$, a detector gain of $6.5 \times$, and a sample rate mass/resolution de $2.00 \mathrm{GS} /$ s. The asphaltene samples for this measure were prepared by the conventional dried-droplet method from solutions of the solid in toluene at enough low concentration necessary to diminish the aggregation of the asphaltenes in the LDI plume.

TGA were carried out on a PerkinElmer Thermogravimetric analyzer TGA 7, with approximately $3 \mathrm{mg}$ of solid asphaltene sample placed in a macro platinum cell. The samples were heated at a rate of $10{ }^{\circ} \mathrm{C} / \mathrm{min}$ from 30 to $850{ }^{\circ} \mathrm{C}$ and held for $30 \mathrm{~min}$ at $850{ }^{\circ} \mathrm{C}$. The weight loss versus time was recorded. During the experiment, the reaction chamber was purged with nitrogen to avoid oxidation and to remove volatile reaction products from the chamber.

FTIR measurements were realized on a Thermo Scientific Nicolet 6700 spectrometer, equipped with a DTGS detector. The solid-phase 

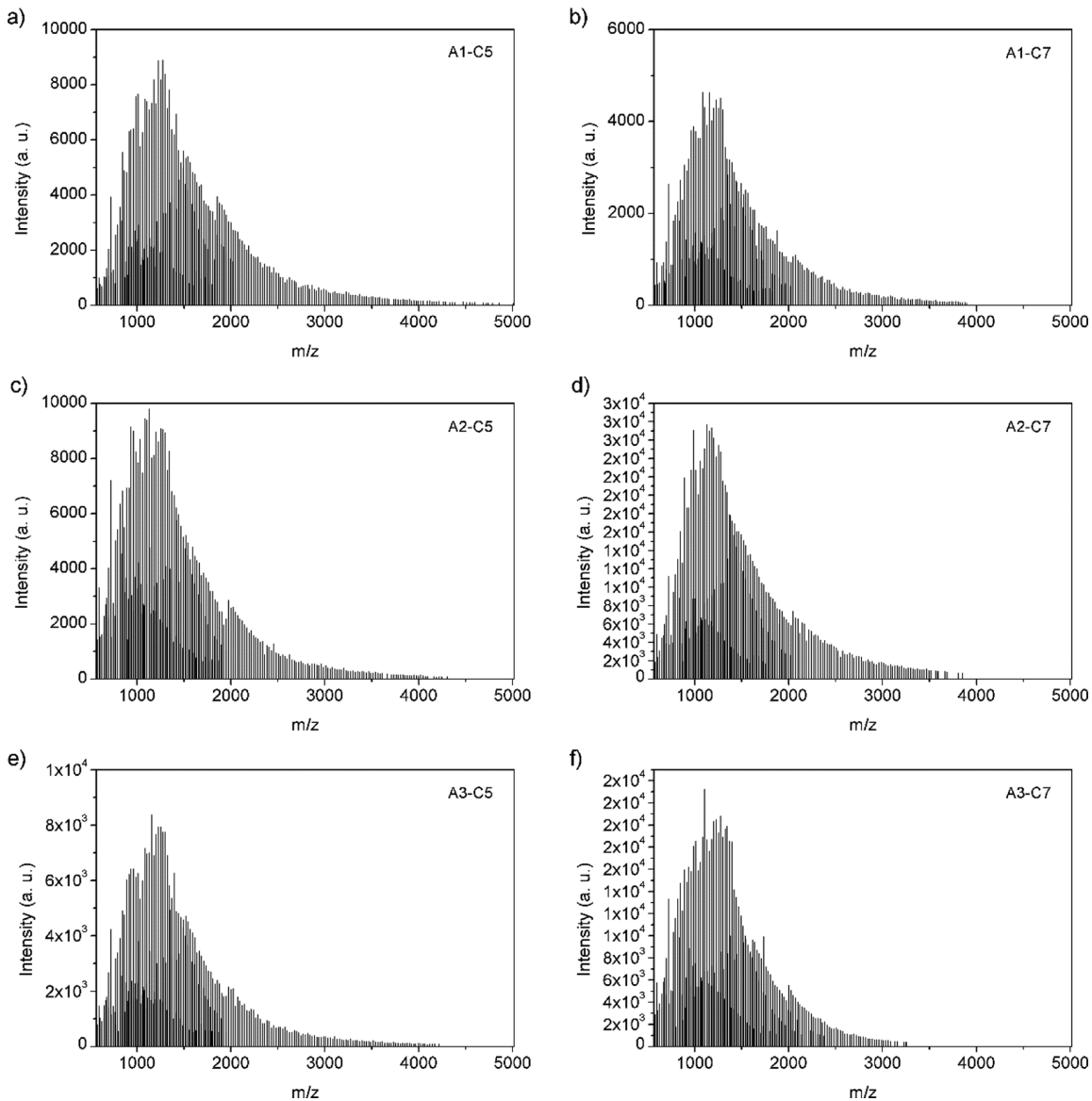

Figure 1. LDI-MS for (a) A1-C5, (b) A1-C7, (c) A2-C5, (d) A2-C7, (e) A3-C5, and (f) A3-C7 asphaltene samples.

spectra of asphaltenes were measured using the $\mathrm{KBr}$ pellet technique in the range from 4000 to $400 \mathrm{~cm}^{-1}$ with a resolution of $0.5 \mathrm{~cm}^{-1}$.

${ }^{1} \mathrm{H}$ NMR spectra were carried out on a Bruker NEO 750 spectrometer operating at ${ }^{1} \mathrm{H}$ resonance frequency of $750 \mathrm{MHz}$. The spectra were obtained as $\mathrm{CDCl}_{3}$ solution with a pulse width of 11.5 ps, recycle delay of $2 \mathrm{~s}$, tube diameter of $5 \mathrm{~mm}$, spectral width of 16 ppm, and 128 scans.

The XRD data were collected at ambient conditions by using Philips diffractometer with a monochromatic $\mathrm{Cu} K \alpha$ radiation $(\lambda=$ $1.5406 \AA)$. The instrument has a control unit type PW 1710, a vertical goniometer PW1820/00, and a generator Enraf Nonius FR590, operating at $40 \mathrm{Kv}$ and $30 \mathrm{~mA}$. The diffractograms were recorded in the range of $2 \theta-70 \theta$ with a step of $0.02 \theta$ and $2 \mathrm{~s}$ per step count time. The solid samples were deposited over the $\mathrm{Si}(511)$ crystal.

The Raman spectra of the asphaltene fractions in the solid phase were measure on a triple-monochromator spectrometer Raman Horiba Jobin Yvon T64000 set in double-subtractive/single configuration and equipped with a charge coupled device (CCD) camera as the detector and a confocal microscope. All spectra were recorded using a $514.5 \mathrm{~nm}$ excitation line of an argon ion laser, in the region between 4000 and $800 \mathrm{~cm}^{-1}$ with an acquisition time of $20 \mathrm{~s}$ and 8 scans.

\section{RESULTS AND DISCUSSION}

Elemental Analysis. The elemental analysis (C, H, N, O, and $\mathrm{S}$ ) of asphaltenes obtained from Comodoro Rivadavia, Rio Negro, and La Pampa crude oils with $n$-pentane (C5) and $n$ heptane (C7) is presented in Table 1.

The asphaltenes prepared by using $n$-heptane as the precipitating medium are considerably different than those obtained by employing $n$-pentane. Thus, the hydrogen-tocarbon atomic ratio of the $n$-heptane precipitate is lower than that of the $n$-pentane precipitate, showing a higher degree of aromaticity when the $n$-heptane is used. Nitrogen-to-carbon, oxygen-to-carbon, and sulfur-to-carbon ratios are commonly higher in the asphaltenes precipitated with $n$-heptane, indicating higher proportions of the heteroelements in the fraction. ${ }^{17}$ These results are similar to those observed for asphaltenes of different origins. $16,17,20$

Laser Desorption Ionization Mass Spectrometry. The LDI-MS spectra are shown in Figure 1, and the average molecular weights extracted from this spectra are listed in Table 1. As shown in this table, the number-average molecular weights $\left(M_{\mathrm{n}}\right)$, weight-average molecular weights $\left(M_{\mathrm{w}}\right)$, and polydispersity index $\left(D_{\mathrm{m}}\right)$ of these values for all of the asphaltenes are similar, and no significant difference was observed between asphaltenes precipitated with different solvents.

It has been shown by Martínez-Haya and co-workers ${ }^{21-24}$ that the apparent $M_{\mathrm{W}}$ of maximum abundance and the width of the MWD obtained by LDI measurements are strongly dependent on the laser surface power density and the asphaltene surface mass density. Consequently, to avoid the occurrence of the self-aggregation of asphaltenes, diluted samples, and low laser energies or both must be employed. On the other hand, it has been suggested that heavier molecular mass distributions are obtained with higher laser surface power because only at high pulse energy are the heavier components of asphaltenes efficiently desorbed and ionized. ${ }^{25-27}$ The LDI spectrum is expected to approach fairly well the MWD of asphaltene monomers, although a small contribution from fragmentation and aggregation cannot be discarded. Further- 
more, the LDI spectra were possible to observe the aromatic peak progressions with a spacing of 24 mass units which could be attributed to natural $\mathrm{PAH}$ asphaltene constituents. Recently, some authors attribute this sequence of $\mathrm{C}_{2}$ bands to fullerene allotropic forms generated by the action of laser radiation. ${ }^{28-32}$

Thermogravimetric Analysis. The TGA was used to characterize the temperature profile of decomposition of the Argentinian asphaltene samples. Figure 2 shows the mass loss

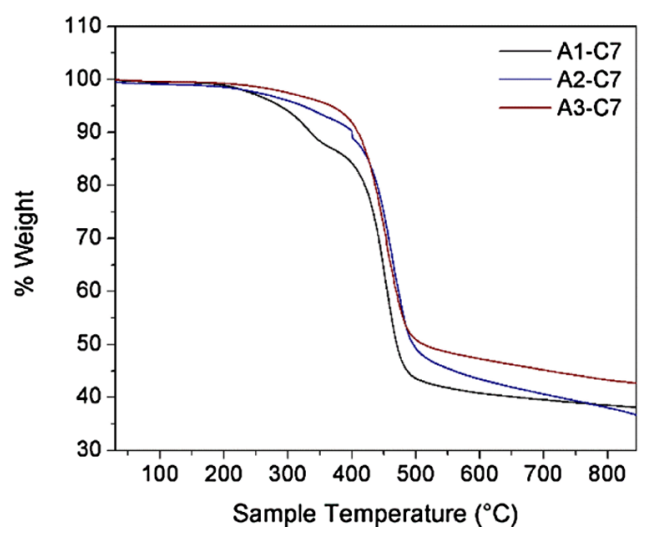

Figure 2. TGA of asphaltene samples extracted in $n$-heptane solvent under the nitrogen atmosphere.

as a function of temperature for three different samples of asphaltenes extracted with $n$-heptane solvent. The mass loss for different temperature ranges are detailed in Table 2 . The first

Table 2. Mass Loss at Different Temperature Ranges for Argentinian Asphaltenes Extracted with $n$-Heptane Solvent

\begin{tabular}{|cccc} 
temperature range $\left({ }^{\circ} \mathrm{C}\right)$ & $\mathrm{A} 1-\mathrm{C} 7(\%)$ & $\mathrm{A} 2-\mathrm{C} 7(\%)$ & $\mathrm{A} 3-\mathrm{C} 7(\%)$ \\
\hline $200-365$ & 12.5 & 7.2 & 4.7 \\
$365-550$ & 44.5 & 44.8 & 46.8 \\
$550-800$ & 5.2 & 15.1 & 7.0
\end{tabular}

mass reduction between 280 and $365^{\circ} \mathrm{C}$ has place only for $\mathrm{A} 1$ sample because of lower molecular weight fragments. The second mass loss of about 44-45\% occurs between 365 and $550{ }^{\circ} \mathrm{C}$ corresponding to asphaltene fraction decompositions in all samples with the maximum rate of weight loss at 454, 465 , and $455{ }^{\circ} \mathrm{C}$ for samples $\mathrm{A} 1, \mathrm{~A} 2$, and $\mathrm{A} 3$, respectively. Finally, the total weight loss was $65-55$, and a $35-45 \%$ of weight remains as coke at $850{ }^{\circ} \mathrm{C}$. The thermogravimetric curves observed for the decomposition are in good agreement with the previous studies. ${ }^{33}$

Infrared Spectroscopy. FTIR spectra of asphaltene samples obtained with $n$-pentane and $n$-heptane as a precipitating medium are shown in Figure 3, and the assignment of different bands is presented in Table 3 based on the previous reports. ${ }^{34}$ All of the spectra were normalized based on the band located at $2923 \mathrm{~cm}^{-1}$, as usual.

Table 3. Assignment of the Vibration Modes for the Main Functional Groups Observed in the Infrared Spectra of the Argentinian Asphaltenes

\begin{tabular}{ll}
$\begin{array}{c}\text { wavenumbers } \\
\left(\mathrm{cm}^{-1}\right)\end{array}$ & \multicolumn{1}{c}{ assignation } \\
3452 & $\mathrm{O}-\mathrm{H}, \mathrm{N}-\mathrm{H}$ stretching \\
3047 & aromatic $\mathrm{C}-\mathrm{H}$ stretching \\
2952 & aliphatic $\mathrm{CH}_{3}$ stretching asymmetric \\
2923 & aliphatic $\mathrm{CH}_{2}$ stretching asymmetric \\
2895 & aliphatic $\mathrm{C}-\mathrm{H}$ tertiary stretching \\
2872 & aliphatic $\mathrm{CH}_{2}$ stretching symmetric \\
2850 & aliphatic $\mathrm{CH}_{3}$ stretching symmetric \\
1741 & alkyl chain $\mathrm{C}=\mathrm{O}$ stretching \\
1692 & aryl ketone or aryl acid C=O stretching \\
1600 & $\mathrm{C}=\mathrm{C}_{\text {conjugated stretching }}$ \\
1452 & $\mathrm{C}-\mathrm{CH}_{3}$ or $\mathrm{C}-\mathrm{CH}_{2}$ asymmetric bending \\
1374 & $\mathrm{C}-\mathrm{CH}_{3}$ or $\mathrm{C}-\mathrm{CH}_{2}$ symmetric bending \\
1030 & $\mathrm{C}-\mathrm{O}, \mathrm{C}-\mathrm{Nor} \mathrm{S}=\mathrm{O}$ stretching \\
870 & aromatic $\mathrm{C}-\mathrm{H}$ deformation out of plane $(1$ isolated $\mathrm{H})$ \\
810 & aromatic $\mathrm{C}-\mathrm{H}$ deformation out of plane $(2$ adj. $\mathrm{H})$ \\
750 & aromatic $\mathrm{C}-\mathrm{H}$ deformation out of plane $(3$ adj. $\mathrm{H})$ \\
720 & $\mathrm{CH} \mathrm{H}_{2}$ rocking in chains, $(\mathrm{CH})_{n} n \geq 4$
\end{tabular}

Qualitatively, the infrared spectra of asphaltenes A1, A2, and A3 are quite similar to each other, and the main features agree with previously reported spectra. It is well-known that the quantitative analysis on selected infrared absorptions gives information on the asphaltene structure. ${ }^{2,35}$

In this work, four of these indexes $\left(\mathrm{CH}_{2} / \mathrm{CH}_{3}\right.$ ratio, $W, f_{\mathrm{a}}$ and $\mathrm{C}=\mathrm{O}$ index) were calculated based on peak areas, which were determined by FTIR spectra deconvolution (Table 4). The $\mathrm{CH}_{2} / \mathrm{CH}_{3}$ ratio was calculated directly from the band intensities at 2923 and $2952 \mathrm{~cm}^{-1}$ assigned to the $\mathrm{C}-\mathrm{H}$ stretch of $\mathrm{CH}_{2}$ and $\mathrm{CH}_{3}$ groups, respectively. This relation is proportional to the length of the side alkyl chains; therefore, a higher index corresponds to longer aliphatic chains. The results show that in both extraction solvents, the asphaltenes called A1 have longer chain lengths than A2 and A3. In
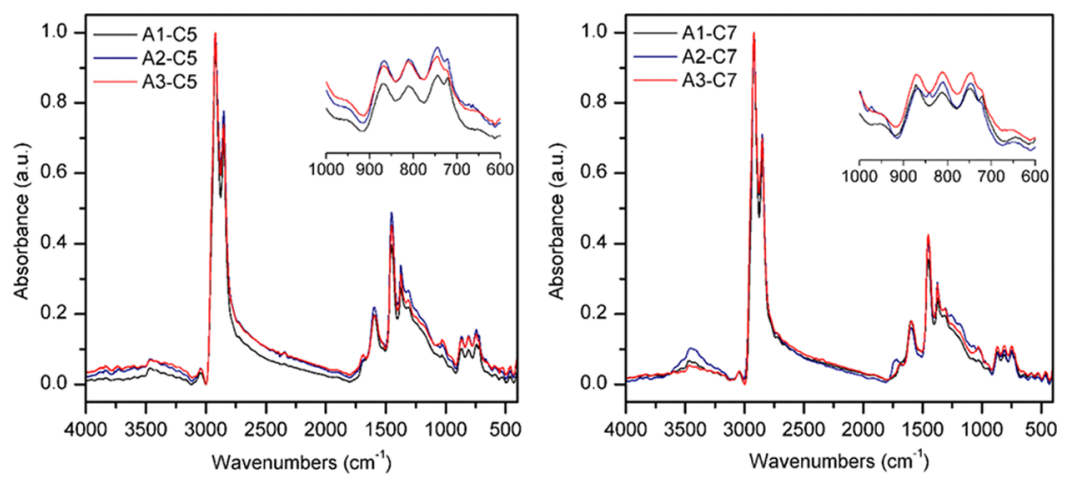

Figure 3. Comparison of the FTIR spectra for the asphaltenes samples extracted with (a) n-pentane and (b) $n$-heptane solvents. 
Table 4. Average Structural Parameters for Argentinian Asphaltenes Extracted with $n$-Pentane and $n$-Heptane Solvents Obtained from FTIR Spectra

\begin{tabular}{|c|c|c|c|c|c|c|c|}
\hline parameters & equation & $\mathrm{A} 1-\mathrm{C} 5$ & $\mathrm{~A} 1-\mathrm{C} 7$ & $\mathrm{~A} 2-\mathrm{C} 5$ & $\mathrm{~A} 2-\mathrm{C} 7$ & $\mathrm{~A} 3-\mathrm{C} 5$ & $\mathrm{~A} 3-\mathrm{C} 7$ \\
\hline $\mathrm{CH}_{2} / \mathrm{CH}_{3}$ & $A_{2923} / A_{2952}$ & 6.74 & 8.44 & 4.60 & 5.54 & 5.87 & 6.56 \\
\hline$W$ & $A_{870} / A_{765}$ & 0.87 & 1.06 & 0.85 & 0.87 & 0.84 & 0.88 \\
\hline degree of condensation & $A_{3047} / A_{1600}$ & 0.08 & 0.07 & 0.11 & 0.05 & 0.20 & 0.10 \\
\hline aromaticity & $A_{3047} /\left(A_{2850}+A_{2872}+A_{2895}+A_{2923}+A_{2952}+A_{3047}\right)$ & 0.02 & 0.01 & 0.02 & 0.01 & 0.03 & 0.02 \\
\hline $\mathrm{C}=\mathrm{O}$ index & $\left(A_{1692}+A_{1741}\right) /\left(A_{1600}+A_{1692}+A_{1741}\right)$ & 0.08 & 0.05 & 0.05 & 0.21 & 0.10 & 0.05 \\
\hline
\end{tabular}

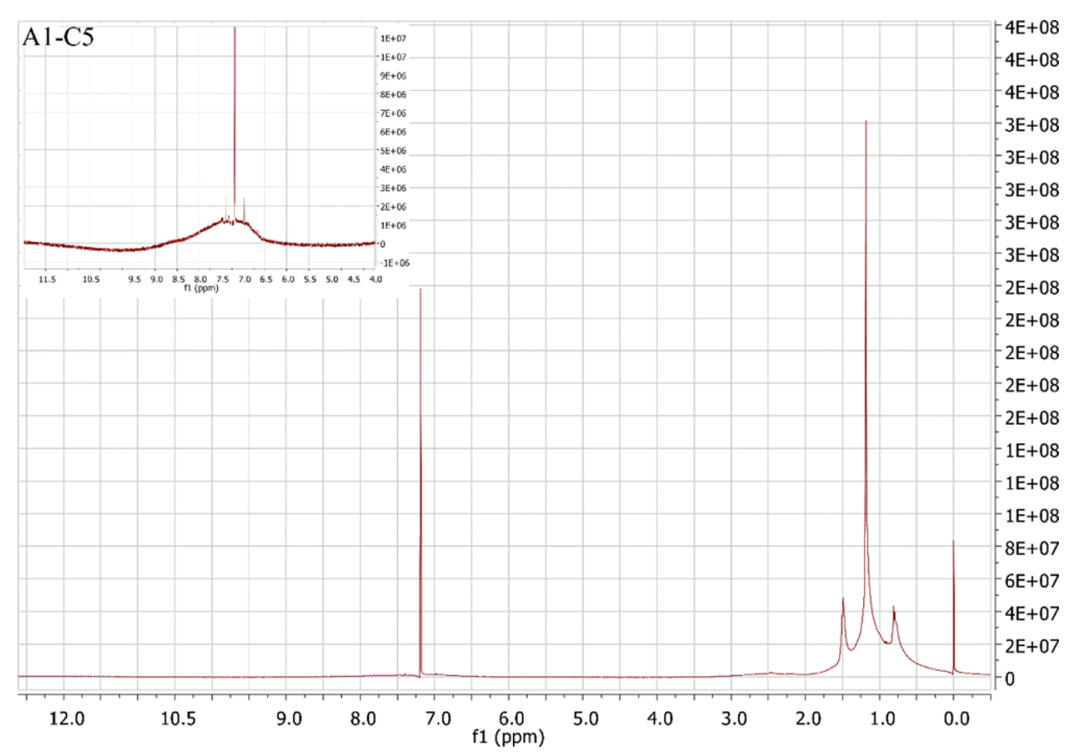

Figure 4. ${ }^{1} \mathrm{H}$ NMR spectrum of $\mathrm{A} 1-\mathrm{C} 5$ asphaltene in $\mathrm{CDCl}_{3}$.

addition, the chain length of asphaltenes precipitated with $n$ heptane is slightly higher than that of those separated by $n$ pentane.

As shown in Figure 3 and Table 3, three signals with similar intensities appear in the region $900-700 \mathrm{~cm}^{-1}$ for all samples analyzed. These bands are associated with $\mathrm{C}-\mathrm{H}$ aromatic outof-plane deformation, where the aromatic ring has only a hydrogen substituent ( 1 isolated $\mathrm{H}$ located at $870 \mathrm{~cm}^{-1}$ ), two hydrogens adjacent substituents of the aromatic ring $(2$ adj. $\mathrm{H}$ at $810 \mathrm{~cm}^{-1}$ ), and three adjacent hydrogens ( 3 adj. $\mathrm{H}$ at 750 $\mathrm{cm}^{-1}$ ) that can be distinctly characterized. ${ }^{34}$

A group of bands falling between 900 and $700 \mathrm{~cm}^{-1}$ give information on the different arrangements of hydrogen atoms per ring occurring in the molecule. Thus, the possible hypothetical structure for Argentinian asphaltene is believed to consist of pericondensed system which is characterized by the presence of three bands in this region assigned to the $\mathrm{C}-\mathrm{H}$ aromatic out-of-plane deformation of 1,2 , and 3 adjacent hydrogen. $^{34}$

The molecular parameter called $W$ index can be obtained from the ratio between the intensity of aromatic $\mathrm{C}-\mathrm{H}$ out of plane deformation with 1 adjacent hydrogen (located at 870 $\mathrm{cm}^{-1}$ ) and the intensity of the same with three adjacent hydrogen FTIR bands (at ca. $750 \mathrm{~cm}^{-1}$ ). This $W$ index is related to the degree of condensation and the substitution of aromatic rings. ${ }^{2}$ Thus, the degree of substitution calculated for the asphaltenes separated by $n$-heptane and $n$-pentane varies between 0.8 and 1 .

The aromaticity index, $f_{a}$, reflects the relative abundance of aromatic versus aliphatic carbon and can be calculated by the ratio between the intensity of aromatic $\mathrm{C}-\mathrm{H}$ stretch (3047 $\mathrm{cm}^{-1}$ ) with the sum of aromatic and aliphatic $\mathrm{C}-\mathrm{H}$ stretching modes. The degree of condensation index, calculated as $A_{3047} /$ $A_{1600}$, is proportional to the ratio of aromatic $\mathrm{C}-\mathrm{H}$ to aromatic $\mathrm{C}=\mathrm{C}$.

The carbonyl index $(\mathrm{C}=\mathrm{O}$ index $)$ is related to the content of carbonyl groups in the asphaltene molecules. The index is obtained by the ratio between the intensities of carbonyl bands located at 1741 and $1692 \mathrm{~cm}^{-1}$ and the sum of $\mathrm{C}=\mathrm{O}$ and $\mathrm{C}=$ $\mathrm{C}$ bands. ${ }^{35}$ The values observed for this parameter were similar for different samples except to A2-C7 that show in the FTIR spectra a more intense carbonyl bands.

Proton Nuclear Magnetic Resonance Spectroscopy. ${ }^{1} \mathrm{H}$ NMR spectra of asphaltenes obtained with $n$-pentane and $n$-heptane as a precipitating medium are presented in Figure 4. The assignments of regions in the NMR spectra were based on previous investigations ${ }^{36-38}$ and are summarized in Table 5. The intensities of various protons were calculated by peak integration and are listed in Table 6.

The most intense peak in the ${ }^{1} \mathrm{H}$ NMR spectra of all of the samples is observed for the $\mathrm{H}_{\beta}$ (between 1.1 and $1.9 \mathrm{ppm}$ ) with a relative percentage between 50 and $60 \%$, followed in abundance by $\mathrm{H}_{\gamma}(0.5-1.1 \mathrm{ppm}), \mathrm{H}_{\alpha}(1.9-3.5 \mathrm{ppm})$, and finally by a less amount of aromatic hydrogen, $\mathrm{H}_{\mathrm{ar}}(6.0-9.3$ ppm). It is observed that $\mathrm{Al}$ contains a higher amount of $\mathrm{H}_{\beta}$ and a lower quantity of $\mathrm{H}_{\alpha}$ than the other samples measured, indicating that $\mathrm{A} 1$ has longer chain lengths and lesser degree of substitution.

It is possible to obtain the structural information from NMR spectra by estimations of some average structural parameters. ${ }^{37,39,40}$ The main molecular parameters derived from NMR spectra were calculated and listed in Table 6. They are the 
Table 5. Chemical Shift Assignments for the ${ }^{1} \mathrm{H}$ NMR Spectrum

\begin{tabular}{|c|c|c|}
\hline $\begin{array}{l}\text { chemical } \\
\text { shift range } \\
\text { (ppm) }\end{array}$ & assignation & $\begin{array}{l}\text { hydrogen } \\
\text { type }\end{array}$ \\
\hline $0.5-1.1$ & $\begin{array}{l}\mathrm{CH}_{3} \text { of paraffins ( } n \text { - and iso-); paraffinic } \\
\text { hydrogen } \gamma \text { and more to aromatic systems }\end{array}$ & $\mathrm{H}_{\gamma}$ \\
\hline $1.1-1.4$ & $\begin{array}{l}\mathrm{CH}_{2} \text { of paraffins ( } n \text { - and iso-), } \mathrm{CH} \text { of isoparaffins, } \\
\text { and } \mathrm{CH} \text { and } \mathrm{CH}_{2} \text { of naphthenes; paraffinic } \\
\text { hydrogen } \beta \text { to aromatic systems }\end{array}$ & $\mathrm{H}_{\beta}$ \\
\hline $1.4-1.9$ & $\begin{array}{l}\mathrm{CH} \text { and } \mathrm{CH}_{2} \text { of naphthenes; mostly } \beta-\mathrm{CH} \text { and } \\
\beta-\mathrm{CH}_{2} \text { to aromatic systems }\end{array}$ & \\
\hline $1.9-2.1$ & $\alpha-\mathrm{CH}_{2}$ to olefins & $\mathrm{H}_{\alpha}$ \\
\hline $2.1-2.3$ & $\alpha-\mathrm{CH}_{3}$ to aromatic carbons & \\
\hline $2.3-3.5$ & $\alpha-\mathrm{CH}$ and $\alpha-\mathrm{CH}_{2}$ to aromatic carbons & \\
\hline $6.0-7.2$ & $\mathrm{CH}$ of mono-ring aromatics & $\mathrm{H}_{\mathrm{ar}}$ \\
\hline $7.2-8.3$ & $\begin{array}{l}\mathrm{CH} \text { of di-ring aromatics and some tri- andtetra-ring } \\
\text { aromatics }\end{array}$ & \\
\hline $8.3-8.9$ & $\mathrm{CH}$ of some tri- and tetra-ring aromatics & \\
\hline $8.9-9.3$ & $\mathrm{CH}$ of some tetra-ring aromatics & \\
\hline
\end{tabular}

Table 6. Average Structural Parameters ${ }^{a}$ for Argentinian Asphaltenes Extracted with $n$-Pentane and $n$-Heptane Solvents Obtained from ${ }^{1} \mathrm{H}$ NMR Spectra

\begin{tabular}{|c|c|c|c|c|c|c|}
\hline hydrogen type & $\mathrm{A} 1-\mathrm{C} 5$ & $\mathrm{~A} 1-\mathrm{C} 7$ & $\mathrm{~A} 2-\mathrm{C} 5$ & $\mathrm{~A} 2-\mathrm{C} 7$ & $\mathrm{~A} 3-\mathrm{C} 5$ & $\mathrm{~A} 3-\mathrm{C} 7$ \\
\hline $\mathrm{H}_{\gamma}$ & 20.61 & 22.50 & 21.46 & 18.79 & 23.26 & 21.08 \\
\hline $\mathrm{H}_{\beta}$ & 61.75 & 63.57 & 54.90 & 54.60 & 50.64 & 54.57 \\
\hline $\mathrm{H}_{\alpha}$ & 12.18 & 8.90 & 17.94 & 20.23 & 20.73 & 17.47 \\
\hline $\mathrm{H}_{\mathrm{ar}}$ & 5.46 & 5.02 & 5.71 & 6.39 & 5.37 & 6.88 \\
\hline parameters & $\mathrm{A} 1-\mathrm{C} 5$ & $\mathrm{~A} 1-\mathrm{C} 7$ & $\mathrm{~A} 2-\mathrm{C} 5$ & $\mathrm{~A} 2-\mathrm{C} 7$ & $\mathrm{~A} 3-\mathrm{C} 5$ & $\mathrm{~A} 3-\mathrm{C} 7$ \\
\hline aromaticity & 0.05 & 0.05 & 0.05 & 0.06 & 0.05 & 0.06 \\
\hline$C_{\text {ar subs }}$ & 2.23 & 1.77 & 3.14 & 3.17 & 3.86 & 2.54 \\
\hline$n$ & 7.76 & 10.67 & 5.26 & 4.63 & 4.57 & 5.33 \\
\hline $\begin{array}{l}N_{\mathrm{B}} \text {, number of } \\
\text { branches }\end{array}$ & 0.59 & 0.40 & 0.84 & 1.08 & 0.89 & 0.83 \\
\hline
\end{tabular}

aromaticity index, the number of substituted aromatic carbons $\left(\mathrm{C}_{\mathrm{ar} \text { subs }}\right)$, the average of alkyl chain length $(n)$, and number of branches $\left(N_{\mathrm{B}}\right)$.

The calculated values for the aromaticity are similar in all samples and show a very well agreement with those observed by FTIR spectroscopy discussed in the previous section. The number of substituted aromatic carbons $\left(\mathrm{C}_{\text {ar subs }}\right)$ varies between 2 and 4, showing smaller values in the asphaltenes extracted with $n$-heptane. This could be because of a higher degree of substitution or a major aromatic condensation.

The average values of alkyl length chains calculated are higher for the asphaltenes A1 than A2 and A3, using both $n$ pentane and $n$-heptane. In addition, the chain length of asphaltenes separated by $n$-heptane is slightly higher than the asphaltenes extracted by $n$-pentane, in good agreement with the results obtained from FTIR spectra.

X-ray Diffraction. The XRD patterns of $n$-pentane and $n$ heptane asphaltenes are shown in Figure S3. The diffractograms are very similar for six samples and show three characteristic peaks: $(1)$ the $(002)$ bands at $2 \theta \approx 25^{\circ}$ attributed to a graphite-like structure of condensed aromatic rings; (2) the $\gamma$ band at $2 \theta \approx 19^{\circ}$ because of aliphatic and not condensed aromatic fraction; and (3) a third diffraction (001) bands, at low angles attributed to a spatial order of the graphitic nuclei of the asphaltene aggregates. The (001) band is detectable generally for the more aromatic asphaltenes. ${ }^{41-44}$

Different structural parameters can be obtained from the XRD patterns. ${ }^{42,45-48}$ The diameter of the aromatic planar sheet $\left(L_{\mathrm{a}}\right)$, the height of the crystallite in the $c$-axis direction $\left(L_{c}\right)$, the distance between two aromatic sheets $\left(d_{\mathrm{m}}\right)$, the average number of stacked aromatic sheets $(M)$ per one cluster and the distance between two saturated chains $\left(d_{\gamma}\right)$, the aromaticity $\left(f_{\mathrm{a}}\right)$, and the average numbers of aromatic rings in one aromatic sheet $\left(R_{\mathrm{a}}\right)$ have been determined in the present study.

The diffractograms were normalized, and $\gamma$ and (002) bands were resolved employing the methods proposed in earlier studies. $^{45}$ The background was established by drawing a straight line that connected data from zones within the observed profile that lacked diffraction contributions. All of the diffractograms plotted against $\sin (\theta) / \lambda$ were deconvoluted as the sum of Gaussian distributions, and the bandwidth at halfheight $\left(B_{1 / 2}\right)$ was obtained for (002) and (001) bands (see Table S1). Thus, several crystallite parameters have been obtained, following the equations detailed in Table 7 .

Table 7. Crystallite Parameters and Aromaticity Extracted from XRD Diffractograms for Different Asphaltene Samples $^{a}$

$\begin{array}{ccccccc} & \text { A1-C5 } & \text { A1-C7 } & \text { A2-C5 } & \text { A2-C7 } & \text { A3-C5 } & \text { A3-C7 } \\ 2 \theta_{(10)} & 47.2 & 48.4 & 48.4 & 47.6 & 47.8 & 48.3 \\ 2 \theta_{(002)} & 25.4 & 24.7 & 25.0 & 25.0 & 24.7 & 24.7 \\ 2 \theta_{\gamma} & 19.2 & 18.7 & 18.8 & 18.7 & 18.7 & 19.0 \\ \text { parameters } & \text { A1-C5 } & \text { A1-C7 } & \text { A2-C5 } & \text { A2-C7 } & \text { A3-C5 } & \text { A3-C7 } \\ d_{\mathrm{m}} & 3.50 & 3.60 & 3.56 & 3.56 & 3.60 & 3.60 \\ d_{\gamma} & 5.77 & 5.93 & 5.90 & 5.93 & 5.93 & 5.83 \\ L_{\mathrm{a}} & 9.76 & 9.76 & 15.48 & 14.95 & 14.49 & 11.52 \\ L_{c} & 12.99 & 11.11 & 12.99 & 14.41 & 14.10 & 12.17 \\ f_{\mathrm{a}} & 0.14 & 0.13 & 0.09 & 0.23 & 0.21 & 0.24 \\ M & 5 & 4 & 5 & 5 & 5 & 4 \\ R_{\mathrm{a}} & 4 & 4 & 6 & 6 & 5 & 4\end{array}$

${ }^{a_{T}}$ The values of distances $d_{\mathrm{m}}, d_{\gamma}, L_{a}$, and $L_{c}$ are expressed in $\AA$. Equations: $d_{\mathrm{m}}=\lambda /(2 \sin \theta(002)), d_{\gamma}=5 \lambda /\left(8 \sin \theta_{\gamma}\right), L_{\mathrm{a}}=0.92 /$ $\mathrm{B}_{1 / 2(10)}, L_{\mathrm{c}}=0.45 / \mathrm{B} 1 / 2(002), f_{\mathrm{a}}=\mathrm{A}_{(002)} /\left(\mathrm{A}_{(002)}+\mathrm{A}_{\gamma}\right), M=\left(L_{\mathrm{c}} /\right.$ $\left.d_{\mathrm{m}}\right)+1, R_{\mathrm{a}}=L_{\mathrm{a}} / 2.667$.

The layer distance between two aromatic sheets $\left(d_{\mathrm{m}}\right)$ was estimated from the maximum of the graphene (002) band using Bragg's equation, and the distance between two aliphatic chains $\left(d_{\gamma}\right)$ was calculated with the same equation from $\theta_{\gamma}$.

The average size of the aromatic clusters perpendicular to the plane of the sheet $\left(L_{c}\right)$ has been estimated using the Scherrer crystallite size formula $0.45 / B_{1 / 2(002)}$, where $B_{1 / 2}$ is the bandwidth at half-height and the number of aromatic sheets associated in a stacked cluster, $M$, has been determined from the ratio between $L_{c}$ and $d_{\mathrm{m}}$ values. ${ }^{42,45}$

In addition, the diameter of the aromatic planar sheet $\left(L_{\mathrm{a}}\right)$ has been calculated from the (10) band by using the equation $0.92 / B_{1 / 2(10)}$. The average number of aromatic rings per sheet $\left(R_{\mathrm{a}}\right)$ can be estimated by the ratio between $L_{\mathrm{a}}$ and the width of a single aromatic unit of $2.667 \AA{ }^{49}$ Finally, the aromaticity $\left(f_{\mathrm{a}}\right)$ was obtained by the ratio of the areas of (002) and the sum of (002) and $\gamma$ bands (see Table 7). ${ }^{50}$

Previous reports suggest that the structure of solid asphaltenes can be considered to be repeating units of stacked condensed aromatic sheets ruled by the $\pi-\pi$ stacking 
interaction. The structural arrangement of one unit is shown schematically in Figure 5 with a highly simplified asphaltene

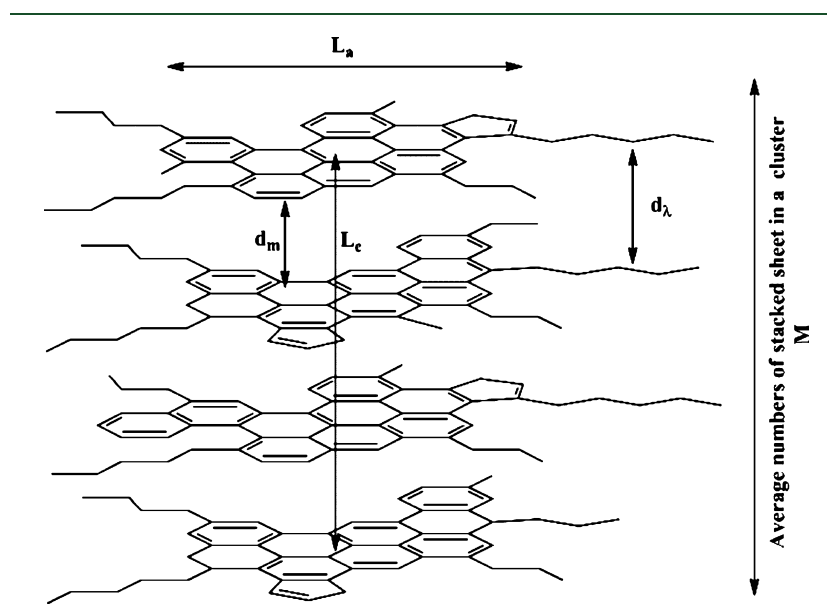

Figure 5. Cross-sectional view of the asphaltene cluster structure model with the main crystallite parameters.

molecule represented as containing only one condensed aromatic ring cluster. Thus, according to XRD, six asphaltene samples studied in this work display an average interlayer distance, $d_{\mathrm{m}}$, in the range from 3.5 to $3.6 \AA$ and the average interchain distance, $d_{\gamma}$, between 5.7 and $5.9 \AA$. The $d_{\mathrm{m}}$ values are in the range of amorphous materials because it is reported for the graphite structure $(3.55 \AA) .{ }^{48}$ Both parameters show values that are typical to the solid petroleum asphaltenes and are slightly smaller than the parameter reported in the resinous material. $^{45}$

The average layer diameter of the sheets, $L_{a}$, ranges from 9.7 to $15.4 \AA$, showing lower values for the A1 separated by $n$ heptane and $n$-pentane than the other sample. The $L_{\mathrm{a}}$ diameter is possibly the most critical feature of the petroleum asphaltene molecule, which allows the estimation of the average number of aromatic rings per sheet. Thus, the estimated $R_{\mathrm{a}}$ numbers are between 4 and 6 , following the same trend.

Furthermore, the macrostructure parameters, $L_{c}$ and $M$, are between 11.1 and $14.4 \AA$ and 4.0 and 5.0, respectively, in good agreement with those reported in the literature. ${ }^{48,49,51,52}$

Finally, the aromaticity index shows values between 0.09 and 0.24. Similar low aromaticity was also reported for other petroleum asphaltene samples, ${ }^{48,52}$ and it is probably because of an important contribution of the saturated groups to the $\gamma$ peak. The relevance of a saturated alkyl chain for the structure of asphaltenes was also pointed out in the analysis of the FTIR and ${ }^{1} \mathrm{H}$ NMR spectra, as discussed previously in this work.

Raman Spectroscopy. The Raman spectra of asphaltenes are characterized by the typical G and D1 bands, generally located at 1580 and $1350 \mathrm{~cm}^{-1}$, respectively. The $\mathrm{G}$ band corresponds to the $\mathrm{C}-\mathrm{C}$ stretching vibration both in the condensed aromatic sheets and in the alkyl chains, whereas the $\mathrm{D} 1$ band is associated with the $\mathrm{C}-\mathrm{C}$ stretching vibration altered by the in-plane defects and the presence of heteroatoms. ${ }^{53}$ Raman spectra of the asphaltene fraction that are dominated by the vibration modes from condensed aromatic sheets are similar to Raman spectra of the graphitic material. $^{54-56}$ Therefore, it is possible to calculate the average size of the aromatic cores by using the Tuinstra and Koenig equation. ${ }^{53}$ In this equation, the ratio between the integrated intensity of the G band with the D1 band is sensitive to the diameter of the aromatic planar sheet, $L_{\mathrm{a}}\left[L_{\mathrm{a}}(\AA)=44\left(I_{\mathrm{G}} / I_{\mathrm{D}}\right)\right]$.

The Raman spectra of the three asphaltenes extracted in $n$ heptane were measured and are shown in Figure S4. The baseline was corrected to remove the fluorescence contribution, and the bands were deconvoluted by using three peaks with Gaussian/Lorentzian functions ${ }^{55}$ centered approximately at 1350,1580 , and $1600 \mathrm{~cm}^{-1}$ assigned to D1, G, and D2 vibrational modes, respectively. The D2 band appears as a shoulder of the $G$ band, and it has been proposed that probably it is originated by defects and inhomogeneities along the intravalley line perpendicular to the crystalline boundary. ${ }^{57,58}$ The calculated $L_{a}$ diameters for the asphaltene samples are listed in Table 8 , showing values in the range of

Table 8. Calculated $L_{\mathrm{a}}$ Diameters $(\AA)$ from Raman Spectra Using Three Peaks Fitting Employing Gaussians/Lorentzian Functions and the Frequencies of D1, G, and D2 Bands

\begin{tabular}{ccccc} 
& \multicolumn{3}{c}{ wavenumbers $\left(\mathrm{cm}^{-1}\right)$} & \\
\cline { 2 - 4 } asphaltene samples & $\mathrm{D} 1$ & $\mathrm{G}$ & $\mathrm{D} 2$ & $L_{\mathrm{a}}=44 I_{\mathrm{G}} / I_{\mathrm{D} 1}(\AA)$ \\
$\mathrm{A} 1-\mathrm{C} 7$ & 1350 & 1577 & 1613 & 12.4 \\
$\mathrm{~A} 2-\mathrm{C} 7$ & 1348 & 1592 & 1616 & 10.1 \\
$\mathrm{~A} 3-\mathrm{C} 7$ & 1338 & 1577 & 1610 & 13.1 \\
\hline
\end{tabular}

10.0-13.1 $\AA$, similar to other asphaltenes previously studied by using Raman spectroscopy, ${ }^{54-56}$ as well as by microscopy. ${ }^{59,60}$ These $L_{\mathrm{a}}$ values suggest an average number of aromatic fused rings per sheet $\left(R_{\mathrm{a}}\right)$ in the asphaltene molecular structure varying between 4 and 5 , in very good agreement with the results obtained from the XRD pattern (Table 7).

Hypothetical Average Structures. As was mentioned before, asphaltenes are a complex mixture of aromatic molecules, and therefore different spectroscopic methods give only mean properties. Each technique employed provides some structural information that is used alone and is usually limited to describe this complex system. To attain more general conclusion, it is necessary to integrate and interrelate results obtained by joint analysis of different methods. Thus, by combining the available experimental data, additional average structural parameter was calculated, as listed in Table 9. Finally, it is possible to integrate all of the information obtained within a hypothetical average structure for the studied asphaltenes.

As mentioned before, several studies indicated that the most probable asphaltene molecular weight is near $750 \mathrm{~g} / \mathrm{mol}^{3,4,61}$ The average $M_{\mathrm{w}}$ obtained in the present work is higher, and aggregation cannot be discarded. Thus, to perform a comparative study of the chemical structure of asphaltenes extracted of different crude oils, an average $M_{\mathrm{w}}$ of $750 \mathrm{Da}$ has been assigned to the six samples. Finally, on combining the average molecular weight with the atomic content extracted from elemental analysis, it is possible to estimate an average molecular formula from which the average structural parameters were calculated (Table 9).

The total hydrogen and carbon atoms $\left(H_{\mathrm{T}}\right.$ and $\left.C_{\mathrm{T}}\right)$ have been obtained from the average molecular formula. Thus, the total saturated carbon atoms $\left(C_{S}\right)$, the total aromatic carbons $\left(C_{\mathrm{ar}}\right)$, the peripheral carbons in a condensed aromatic sheet $\left(C_{\mathrm{P}}\right)$, the substituted aromatic carbons $\left(C_{\text {ar subs }}\right)$, and the unsubstituted aromatic carbons ( $C_{\text {ar unsubs }}$ ) per average molecule of asphaltene could be calculated from ${ }^{1} \mathrm{H}$ NMR data and the $C_{\mathrm{T}}$ value (see Table 9). 


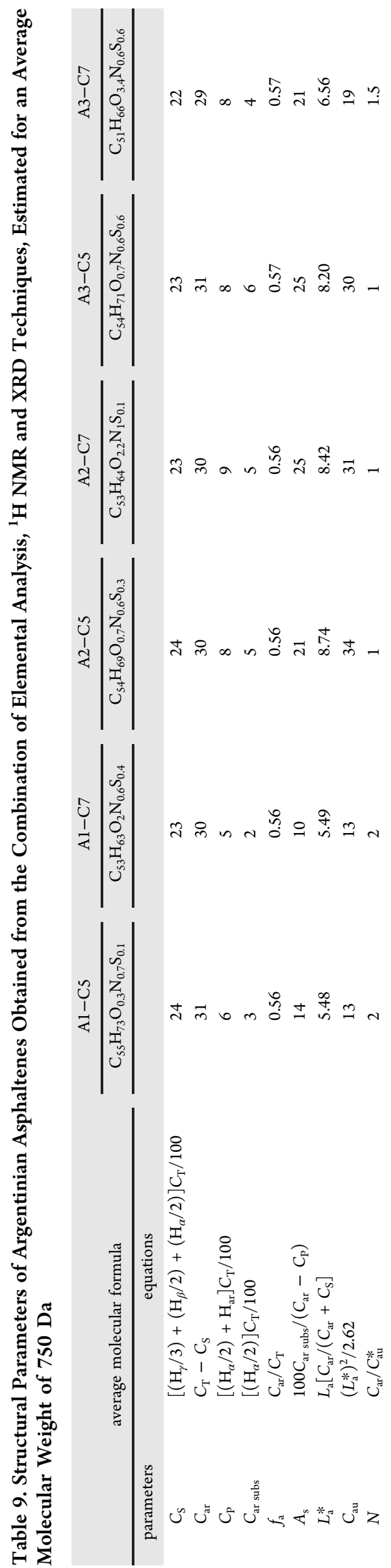

The aromaticity factor, $f_{\mathrm{a}}$, has been calculated as the ratio of aromatic carbons to the total number of saturated and aromatic carbons. The $f_{\mathrm{a}}$ value of approximately 0.5 was obtained for all of the samples studied, indicating that the carbon atoms are nearly equally distributed between aliphatic and aromatic building blocks. The percentage of substituted aromatic rings $\left(A_{\mathrm{s}}\right)$ is between 10 and 25, showing smaller values for $\mathrm{A} 1$.

The number of carbons per aromatic structural unit $\left(C_{\mathrm{au}}\right)$ is related with $L_{a}$ diameter and can be estimated both for pericondensed or catacondensed systems. ${ }^{62}$ In this case, the equation for pericondensation was used because of the lesser proportion of $C_{\mathrm{P}}$ versus $C_{\mathrm{ar}}$ together with the results obtained by FTIR and NMR techniques. In addition, the dimension of the sheet $\left(L_{\mathrm{a}}\right)$ includes the heteroatoms and the carbon atoms of side chains which are contained in the plane of the sheet. This leads to an overestimation in the diameter of the aromatic sheet and can be corrected multiplying $L_{\mathrm{a}}$ by the factor $C_{\mathrm{ar}}$ / $\left(C_{\mathrm{ar}}+C_{\mathrm{S}}\right)$ which is obtained from the preceding NMR analysis $\left(L_{\mathrm{a}}^{*}\right)$ (see Table 9$){ }^{63}$

Last, the number of aromatic structural units per molecule, $N$, was calculated by the ratio $C_{\mathrm{ar}} / C_{\mathrm{au}}$ (Table 9), which was found to vary between 1 and 2 for the asphaltenes studied here, observing the major numbers of sheets for $\mathrm{A} 1$ in both extraction solvent. These results are in good agreement with previous investigations. $4,41,63$

On the basis of the similarity of the average structural parameters of A2 with those of A3 asphaltenes, the same hypothetical average model structures was proposed satisfying the experimental determined parameters (Figure 6). This

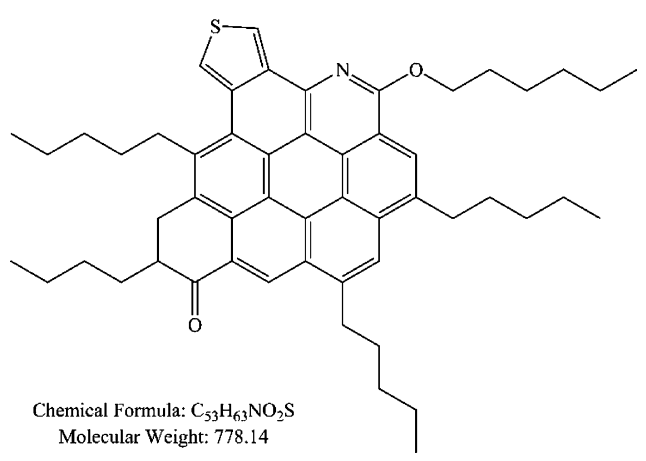

Figure 6. Hypothetical structure proposed for $\mathrm{A} 2$ and $\mathrm{A} 3$ asphaltenes.

model is not unique but provides a good approach to average asphaltene structure and allows estimating some properties of this very complex mixture. For simplicity, the model shown here corresponds to the precipitated asphaltenes using $n$ heptane that have more content of heteroatoms.

The model proposed here for A2 and A 3 asphaltenes closely resembles the "island" type structure with pericondensed rings connected through naphthenic and aliphatic chains. As discussed previously, the presence of a pericondensed system is clearly inferred from the IR spectroscopic data, instead of a catacondensed structure. This result is consistent with the previous reports on asphaltenes, for which the pericondensed arrangement of aromatic rings is also preferred. ${ }^{52}$ The total number of aromatic rings per molecule is $\sim 7$, condensed in one aromatic sheet (interrelating XRD, Raman, and NMR data). The length of the alkyl side chains in the proposed structure has five carbon atoms, in agreement with the values from FTIR and ${ }^{1} \mathrm{H}$ NMR spectroscopies. The content of $C_{S}$, 
$C_{\mathrm{ar}}, C_{\mathrm{P}}$, and $C_{\mathrm{ar} \text { subs }}$ are in good agreement with the values obtained from NMR spectra and elemental analysis. Furthermore, the heteroatoms were inserted in the structural unit respecting the experimental molecular formula, and the functional groups are proposed based on the spectroscopic data. Recently, $\mathrm{S}-\mathrm{K}$ edge XANES spectra of Argentinian petroleum asphaltenes were measured in our group, and the presence of sulfur mainly as sulfides and thiophene has been determined. ${ }^{64}$

On the other hand, the A1 asphaltene fraction extracted from the crude oil with the lower API value shows average structural parameters dissimilar than that of the A2 and A3 fractions. In this case were found smaller number of aromatic fused rings $\left(R_{\mathrm{a}} \approx 3-4\right)$, lesser degree of condensation, higher alkyl side chains ( $\sim 8$ carbons long), and similar aromaticity than the other studied asphaltenes. Thus, the model structure suggested for the Al asphaltene fraction is slightly different, containing two sheets of pericondensed aromatic rings adopting an archipelago-type structure.

\section{CONCLUSIONS}

Six asphaltenes were separated from Argentinian crude oils by using $n$-pentane and $n$-heptane as precipitating solvents and analyzed using a wide variety of spectroscopic techniques. The principal differences found were a higher degree of aromaticity and major proportion of the heteroelements when $n$-heptane was used, in agreement with previous investigations. ${ }^{16,17,20}$

The detailed analysis of spectroscopic (infrared, Raman, and ${ }^{1} \mathrm{H}$ NMR) and XRD data, in combination with elemental analysis and LDI-MS, allow to determine the average structure of the studied asphaltenes.

Thus, the island model with a pericondensed arrangement of the PAH core describes the hypothetical average structures for Argentinian asphaltenes from Rio Negro Norte Block (A2) and La Salina in La Pampa province (A3), whereas an archipelagotype structure with two smaller $\mathrm{PAH}$ sheets with longer alkyl chains seems to better explain the structural features of asphaltenes from San Jorge gulf (A1).

\section{ASSOCIATED CONTENT}

\section{S Supporting Information}

The Supporting Information is available free of charge on the ACS Publications website at DOI: 10.1021/acs.energyfuels. 8 b04318.

Maps of Argentina with the origin regions of study crude oils; solution-state ${ }^{1} \mathrm{H}$ NMR spectrum of A1-C5, A1$\mathrm{C} 7, \mathrm{~A} 2-\mathrm{C} 5, \mathrm{~A} 2-\mathrm{C} 7, \mathrm{~A} 3-\mathrm{C} 5$, and $\mathrm{A} 3-\mathrm{C} 7$ asphaltenes in $\mathrm{CDCl}_{3} ; \mathrm{XRD}$ patterns for asphaltenes samples extracted with (a) n-pentane and (b) n-heptane solvents; areas and the bandwidth at half-height $\left(B_{1 / 2}\right)$ obtained from XRD patterns of different asphaltene samples; and Raman spectra of three Argentinian asphaltenes extracted with $n$-heptane (a) A1-C7, (b) A2-C7, and (c) A3-C7 (PDF)

\section{AUTHOR INFORMATION}

\section{Corresponding Authors}

*E-mail: mgerones@quimica.unlp.edu.ar (M.G.).

*E-mail: erben@quimica.unlp.edu.ar (M.F.E.).

ORCID $\odot$

David Buceta: 0000-0002-3297-6695
M. Arturo López-Quintela: 0000-0002-4842-8028

Mauricio F. Erben: 0000-0001-8467-2784

Notes

The authors declare no competing financial interest.

\section{ACKNOWLEDGMENTS}

This work was supported by the Agencia Nacional de Promoción Científica y Tecnológica, ANPCyT (PICT-20121132 and PICT-2013-2130), and Universidad Nacional de La Plata (11/X-794), Argentina. M.G. and M.F.E. are members of the Scientific Career of CONICET. Y.B.B. is a postdoctoral fellow of CONICET. The authors wish to acknowledge the support of the University of Santiago de Compostela. The authors thank Ruben Nicolás Santillán (YPF Tecnologia S.A. Y-TEC) and Prof. Romano (CEQUINOR) for his help in the measurements of API gravities and Raman spectra, respectively.

\section{REFERENCES}

(1) Sheu, E. Y.; Storm, D. A. Asphaltenes: Fundamentals and Applications; Sheu, E. Y., Mullins, O. C., Eds.; Springer Science +Business Media, LLC: Chicago, 1993.

(2) Mullins, O. C.; Sheu, E. Y. Structures and Dynamics of Asphaltenes; Mullins, O. C., Sheu, E. Y., Eds.; Springer US: Boston, MA, 1998.

(3) Zhang, D.; Creek, J.; Jamaluddin, A.; Marshall, A. G.; Rodgers, R. P.; Mullins, O. C. Asphalthenes-Problematic but Rich in Potential. Oilf. Rev. 2007, 22-43.

(4) Mullins, O. C.; Sheu, E. Y.; Hammami, A.; Marshall, A. G. Asphaltenes, Heavy Oils, and Petroleomics; Springer, 2007.

(5) Groenzin, H.; Mullins, O. C. Molecular Size and Structure of Asphaltenes from Various Sources. Energy Fuels 2000, 14, 677-684.

(6) Mullins, O. C. The Modified Yen Model. Energy Fuels 2010, 24, 2179-2207.

(7) Murgich, J.; Abanero, J. A.; Strausz, O. P. Molecular recognition in aggregates formed by asphaltene and resin molecules from the Athabasca oil sand. Energy Fuels 1999, 13, 278-286.

(8) Sheremata, J. M.; Gray, M. R.; Dettman, H. D.; McCaffrey, W. C. Quantitative molecular representation and sequential optimization of Athabasca asphaltenes. Energy Fuels 2004, 18, 1377-1384.

(9) Dutta Majumdar, R.; Bake, K. D.; Ratna, Y.; Pomerantz, A. E.; Mullins, O. C.; Gerken, M.; Hazendonk, P. Single-Core PAHs in Petroleum- and Coal-Derived Asphaltenes: Size and Distribution from Solid-State NMR Spectroscopy and Optical Absorption Measurements. Energy Fuels 2016, 30, 6892-6906.

(10) Mullins, OC The asphaltenes. Annu Rev Anal Chem (Palo Alto Calif) 2011, 4, 393-418.

(11) Chacón-Patiño, M. L.; Rowland, S. M.; Rodgers, R. P. Advances in Asphaltene Petroleomics. Part 3. Dominance of Island or Archipelago Structural Motif Is Sample Dependent. Energy Fuels 2018, 32, 9106-9120.

(12) López, R. M.; del Luján Mangani, A.; Arbeloa, E. M.; Luiz, M. M.; Gutiérrez, M. I. Singlet Oxygen Production by a Crude Oil from the San Jorge Gulf Basin. Photochem. Photobiol. 2018, 94, 1138-1142.

(13) ASTM D6560: Determination of Asphaltenes (Heptane Insolubles) in Crude Petroleum and Petroleum Products, 2001.

(14) ASTM D4052-15: Standard Test Method for Density, Relative Density, and API Gravity of Liquids by Digital Density Meter; ASTM International: West Conshohocken, PA, 2015.

(15) Speight, J. The Chemistry and Technology of Petroleum, 5th ed.; CRC Press, 2014.

(16) Speight, J. G.; Long, R. B.; Trowbridge, T. D. Factors influencing the separation of asphaltenes from heavy petroleum feedstocks. Fuel 1984, 63, 616-620. 
(17) Speight, J. G.; Moschopedis, S. E. On the Molecular Nature of Petroleum Asphaltenes. Chemistry of Asphaltenes; Advances in Chemistry; American Chemical Society, 1982; Vols. 1-15.

(18) Speight, J. G. Petroleum asphaltenes - Part 1: Asphaltenes, resins and the structure of petroleum. Oil Gas Sci. Technol. 2004, 59, 467-477.

(19) Mitchell, D. L.; Speight, J. G. The solubility of asphaltenes in hydrocarbon solvents. Fuel 1973, 52, 149-152.

(20) Ancheyta, J.; Centeno, G.; Trejo, F.; Marroquín, G.; García, J. A.; Tenorio, E.; Torres, A. Extraction and characterization of asphaltenes from different crude oils and solvents. Energy Fuels 2002, 16, 1121-1127.

(21) Martínez-Haya, B.; Hortal, A. R.; Hurtado, P.; Lobato, M. D.; Pedrosa, J. M. Laser desorption/ionization determination of molecular weight distributions of polyaromatic carbonaceous compounds and their aggregates. Mass Spectrom 2007, 42, 701-713.

(22) Mullins, O. C.; Martínez-Haya, B.; Marshall, A. G. Contrasting Perspective on Asphaltene Molecular Weight. This Comment vs the Overview of A. A. Herod, K. D. Bartle, and R. Kandiyoti. Energy Fuels 2008, 22, 1765-1773.

(23) Hortal, A. R.; Hurtado, P.; Martínez-Haya, B.; Mullins, O. C. Molecular-Weight Distributions of Coal and Petroleum Asphaltenes from Laser Desorption/Ionization Experiments. Energy Fuels 2007, $21,2863-2868$

(24) Hortal, A. R.; Martínez-Haya, B.; Lobato, M. D.; Pedrosa, J. M.; Lago, S. On the determination of molecular weight distributions of asphaltenes and their aggregates in laser desorption ionization experiments. J. Mass Spectrom. 2006, 41, 960-968.

(25) Tanaka, R.; Sato, S.; Takanohashi, T.; Hunt, J. E.; Winans, R. E. Analysis of the molecular weight distribution of petroleum asphaltenes using laser desorption-mass spectrometry. Energy Fuels 2004, 18, $1405-1413$.

(26) Acevedo, S.; Gutierrez, L. B.; Negrin, G.; Pereira, J. C.; Mendez, B.; Delolme, F.; Dessalces, G.; Broseta, D. Molecular weight of petroleum asphaltenes: A comparison between mass spectrometry and vapor pressure osmometry. Energy Fuels 2005, 19, 1548-1560.

(27) Al-Muhareb, E.; Morgan, T. J.; Herod, A. A.; Kandiyoti, R. Characterization of petroleum asphaltenes by size exclusion chromatography, UV-fluorescence and mass spectrometry. Pet. Sci. Technol. 2007, 25, 81-91.

(28) Camacho-Bragado, G. A.; Santiago, P.; Marin-Almazo, M.; Espinosa, M.; Romero, E. T.; Murgich, J.; Rodriguez Lugo, V.; Lozada-Cassou, M.; Jose-Yacaman, M. Fullerenic structures derived from oil asphaltenes. Carbon 2002, 40, 2761-2766.

(29) Pereira, T. M. C.; Vanini, G.; Tose, L. V.; Cardoso, F. M. R.; Fleming, F. P.; Rosa, P. T. V.; Thompson, C. J.; Castro, E. V. R.; Vaz, B. G.; Romão, W. FT-ICR MS analysis of asphaltenes: Asphaltenes go in, fullerenes come out. Fuel 2014, 131, 49-58.

(30) Santos, V. G.; Fasciotti, M.; Pudenzi, M. A.; Klitzke, C. F.; Nascimento, H. L.; Pereira, R. C. L.; Bastos, W. L.; Eberlin, M. N. Fullerenes in asphaltenes and other carbonaceous materials: natural constituents or laser artifacts. Analyst 2016, 141, 2767-2773.

(31) Daaou, M.; Larbi, A.; Martínez-haya, B.; Rogalski, M. A Comparative study of the chemical structure of asphaltenes from Algerian petroleum collected at different stages of extraction and processing. J. Pet. Sci. Eng. 2016, 138, 50-56.

(32) Acevedo, S.; Labrador, H.; Puerta, L.; Bouyssiere, B.; Carrie, H. Analysis of the Photo Conversion of Asphaltenes Using Laser Desorption Ionization Mass Spectrometry: Fragmentation, Ring Fusion, and Fullerene Formation. J. Petrol. Sci. Technol. 2018, 8, $57-69$.

(33) Trejo, F.; Rana, M. S.; Ancheyta, J. Thermogravimetric determination of coke from asphaltenes, resins and sediments and coking kinetics of heavy crude asphaltenes. Catal. Today 2010, 150, 272-278.

(34) Yen, T. F.; Wu, W. H.; Chilingar, G. V. A Study of the Structure of Petroleum Asphaltenes and Related Substances by Infrared Spectroscopy. Energy Sources 1984, 7, 203-235.
(35) Calemma, V.; Iwanski, P.; Nali, M.; Scotti, R.; Montanari, L. Structural Characterization of Asphaltenes of Different Origins. Energy Fuels 1995, 9, 225-230.

(36) Yen, T. F.; Wu, W. H.; Chilingar, G. V. A Study of the Structure of Petroleum Asphaltenes and Related Substances by Proton Nuclear Magnetic Resonance. Energy Sources 1984, 7, 275-304.

(37) Silva, S. L.; Silva, A. M. S.; Ribeiro, J. C.; Martins, F. G.; Da Silva, F. A.; Silva, C. M. Chromatographic and spectroscopic analysis of heavy crude oil mixtures with emphasis in nuclear magnetic resonance spectroscopy: A review. Anal. Chim. Acta 2011, 707, 1837.

(38) Chinelatto Júnior, L. S.; Cabral de Menezes, S. M.; Honorato, H. d. A.; de Oliveira, M. C. K.; Marques, L. C. d. C. DiffusionOrdered Spectroscopy Nuclear Magnetic Resonance as an Alternative Technique to Improve Asphaltene Characterization. Energy Fuels 2018, 32, 2793-2800.

(39) Dickinson, E. M. Structural comparison of petroleum fractions using proton and13C n.m.r. spectroscopy. Fuel 1980, 59, 290-294.

(40) Calemma, V.; Iwanski, P.; Nali, M.; Scotti, R.; Montanari, L. Structural Characterization of Asphaltenes of Different Origins. Energy Fuels 1995, 9, 225-230.

(41) Mullins, O. C.; Sheu, E. Y. Structures and Dynamics of Asphaltenes; Mullins, O. C., Sheu, E. Y., Eds.; Springer US: Boston, MA, 1998; Vol. 39.

(42) Yen, T. F.; Erdman, J. G.; Pollack, S. S. Investigation of the Structure of Petroleum Asphaltenes by X-Ray Diffraction. Anal. Chem. 1961, 33, 1587-1594.

(43) Bolin, T. B.; Birdwell, J. E.; Lewan, M. D.; Hill, R. J.; Grayson, M. B.; Mitra-Kirtley, S.; Bake, K. D.; Craddock, P. R.; Abdallah, W.; Pomerantz, A. E. Sulfur Species in Source Rock Bitumen before and after Hydrous Pyrolysis Determined by X-ray Absorption Near-Edge Structure. Energy Fuels 2016, 30, 6264-6270.

(44) Siddiqui, M. N.; Ali, M. F.; Shirokoff, J. Use of X-ray diffraction in assessing the aging pattern of asphalt fractions. Fuel 2002, 81, 5158

(45) Kamyanov, V. F.; Bodraya, N. V.; Sivirilov, P. P.; Unger, F. G.; Filimonova, T. A.; Chernyavskii, V. N. X-ray diffraction analysis of the resinous-asphaltene com ponents of west siberian crude oil. Pet. Chem. 1989, 29, 1-13.

(46) Tanaka, R.; Sato, E.; Hunt, J. E.; Winans, R. E.; Sato, S.; Takanohashi, T. Characterization of asphaltene aggregates using X-ray diffraction and small-angle X-ray scattering. Energy Fuels 2004, 18, $1118-1125$

(47) El-Sayed, K.; El-Feky, A. A.; Mohamed Bakr, M.; Hamdy, A.; Hegazey, R. M. Fingerprinting of Egyptian asphaltenes using X-ray diffraction and Raman spectrocopy. Int. J. Curr. Res. 2015, 7, 1777717781 .

(48) Andersen, S. I.; Jensen, J. O.; Speight, J. G. X-ray diffraction of subfractions of petroleum asphaltenes. Energy Fuels 2005, 19, 23712377.

(49) Pei, L.; Li, D.; Liu, X.; Cui, W.; Shao, R.; Xue, F.; Li, W. Investigation on Asphaltenes Structures during Low Temperature Coal Tar Hydrotreatment under Various Reaction Temperatures. Energy Fuels 2017, 31, 4705-4713.

(50) Ungár, T.; Gubicza, J.; Ribárik, G.; Pantea, C.; Zerda, T. W. Microstructure of carbon blacks determined by X-ray diffraction profile analysis. Carbon 2002, 40, 929-937.

(51) Dickie, J. P.; Yen, T. F. Macrostructures of the Asphaltic Fractions by Various Instrumental Methods. Anal. Chem. 1967, 39, 1847-1852.

(52) Yen, T. F. Structural Differences Between Asphaltenes Isolated from Petroleum and from Coal Liquid. Chem. Asphaltenes 1982, 195, $39-51$.

(53) Tuinstra, F.; Koenig, J. L. Raman Spectrum of Graphite. J. Chem. Phys. 1970, 53, 1126-1130.

(54) Abdallah, W. A.; Yang, Y. Raman Spectrum of Asphaltene. Energy Fuels 2012, 26, 6888-6896.

(55) Bouhadda, Y.; Bormann, D.; Sheu, E.; Bendedouch, D.; Krallafa, A.; Daaou, M. Characterization of Algerian Hassi-Messaoud 
asphaltene structure using Raman spectrometry and X-ray diffraction. Fuel 2007, 86, 1855-1864.

(56) Riedeman, J. S.; Kadasala, N. R.; Wei, A.; Kenttämaa, H. I. Characterization of Asphaltene Deposits by Using Mass Spectrometry and Raman Spectroscopy. Energy Fuels 2016, 30, 805-809.

(57) Jawhari, T.; Roid, A.; Casado, J. Raman spectroscopic characterization of some commercially available carbon black materials. Carbon 1995, 33, 1561-1565.

(58) Dresselhaus, M. S.; Dresselhaus, G. Intercalation compounds of graphite. Adv. Phys. 2002, 51, 1-186.

(59) Zajac, G.; Corporation, A.; Seth, N. K.; Joseph, J. T. Molecular imaging of petroleum asphaltenes by scanning tunneling microscopy: Verification of structure from $13 \mathrm{C}$ and proton nuclear magnetic resonance data. Scanning Microsc. 1994, 8, 463-470.

(60) Sharma, A.; Groenzin, H.; Tomita, A.; Mullins, O. C. Probing Order in Asphaltenes and Aromatic Ring Systems by HRTEM. Energy Fuels 2002, 16, 490-496.

(61) Mullins, O. C.; Pomerantz, A. E.; Zuo, J. Y.; Dong, C. Downhole Fluid Analysis and Asphaltene Science for Petroleum Reservoir Evaluation. Annu. Rev. Chem. Biomol. Eng. 2014, 5, 325345.

(62) Yen, T. F. Developments in Petroleum Science; ScienceDirect, 1994; Vol. 40, pp 111-123.

(63) Schwager, I.; Farmanian, P. A.; Kwan, J. T.; Weinberg, V. A.; Yen, T. F. Characterization of the microstructure and macrostructure of coal-derived asphaltenes by nuclear magnetic resonance spectrometry and x-ray diffraction. Anal. Chem. 1983, 55, 42-45.

(64) Bava, Y. B.; Geronés, M.; Andrini, L.; Giovanetti, L.; Erben, M. F. Chemical Speciation of Sulphur in Petroleum Asphaltenes Using XANES Spectroscopies, manuscript in preparation. 